\title{
List of Tables, Figures and Extracts
}

\section{Tables}

Table 4.1 Decline of Traditional Spanish forms across generations (\%)

Table 5.1 Phonological contexts for the aspiration of syllable- and word-final /s/ in Spanish

Table 5.2 Distribution of variant use of syllable- and word-final /s/ according to usage and attitudinal factors in the Spanish of Rivera

Table 5.3 Multivariate analysis of the probabilities of co-occurrence of the aspiration of /s/ and usage and attitudinal factors in the Spanish of Rivera $(p<.05, \mathrm{~N}=3,091$ (except where indicated), Input $=0.222$, Log likelihood $=-1627.964)$

Table 5.4 Multivariate analysis of the probabilities of co-occurrence of the deletion of $/ \mathrm{s} /$ and usage and attitudinal factors in the Spanish of Rivera $(p<.05, \mathrm{~N}=3,091$, Input $=0.119$, Log likelihood $=-1113.297)$

Table 5.5 Cross-tabulation of rates of /s/-deletion, as opposed to retention ([s]) or aspiration $([\mathrm{h}])$, according to morphological status and language preference

Table 6.1 Demographic characteristics of the three participant groups

Table 6.2 Comparisons of vowel height (F1) and vowel frontness (F2) in pre-liquid versus other phonetic contexts in English for each of the tense vowels examined

Table 6.3 Comparisons of vowel height (F1) and vowel frontness (F2) in pre-liquid versus other phonetic contexts in Spanish for each of the vowels examined

Table 8.1 Recognition of 'top 20' dialect areas by respondents' country

Table 8.2 'Out of area' commuting data, with recognition levels for Scottish and English dialect areas

Table 10.1 Census data: population, language and religion in selected areas 
Table 11.2 Self-reported medium-of-instruction preferences (\%) of the three largest ethnic groups included in the sample (Luxembourgish, Luxembourgish dual nationality, Portuguese)

\section{Figures}

Figure 1.1 Map of the AISEB fieldwork locations (reproduced, with permission, from Watt et al. 2014)

Figure 1.2 Gridded population map of the United Kingdom (C) Benjamin D. Hennig, Worldmapper Project (www.worldmapper.org)

Figure 1.3 Regions of Britain defined using a spectral modularity optimisation algorithm run on a database of 12 billion landline telephone calls placed over a one-month period. Map (a) after two iterations; (b) final partitioning; (c) after further fine-tuning following M. Newman (2006). From Ratti et al. (2010: e14248, p. 3)

Figure 1.4 Pressure waveform (upper pane) and wide-band spectrogram (lower pane) of the word kit spoken by a 22-year-old male from Berwick

Figure 1.5 Probability density functions for VOT in the four fieldwork localities, by age group

Figure 1.6 Probability density functions for VOT of the voiceless stops $/ \mathrm{p} \mathrm{t} \mathrm{k} /$ in the four fieldwork localities, by age group

Figure 1.7 Proportions of informants in each fieldwork site who ranked their respective national identity labels (Scottish or English) higher in importance than British, by age group

Figure 1.8 Individual and mean group distances, in percentage points, between the Nation and British labels on the Relational Analogue Scale (RAS) in the four fieldwork sites, by speaker age

Figure 1.9 Proportions of informants in each fieldwork site who did not choose British or their respective national identity labels (Scottish or English) during the RAS task, by age group

Figure 2.1 Map of the Fenland in Anglo-Saxon times (from Stafford 1985: 7) 29

Figure 2.2 The sparseness of Fenland settlements in the Domesday Book (Darby 1934: 189)

Figure 2.3 Map from Kurath and Lowman (1970: 17) showing variable realisations of $/ \Lambda /$ on either side of the Fens

Figure 2.4 Viereck's multivariable map of morphological isoglosses, based on the Survey of English Dialects (Viereck 1986b: 250), with Fenland highlighted

Figure 2.5 Viereck's multivariable map of phonological isoglosses, based on the Survey of English Dialects (Viereck 1986b: 245), with Fenland highlighted

Figure 2.6 Viereck's multivariable map of lexical isoglosses, based on the Survey of English Dialects (Viereck 1986a: 734), with Fenland highlighted

Figure 2.7 'Snail' in Eastern England (Kontic 1990: 181)

Figure 3.1 The speech areas of the Eastern States (from Kurath 1949: 91) 
Figure 3.2 The major dialect regions of the continental United States (from Carver 1987: 248)

Figure 3.3 North American English dialects (Map 11.15 from Labov, Ash and Boberg (2006), reproduced with permission)

Figure 4.1 Geographical distribution of consultants $(\mathrm{N}=357)$ across New Mexico and southern Colorado

Figure 4.2 Distribution of fondo and variants of naguas ('slip', the undergarment) across New Mexico and southern Colorado

Figure 4.3 Distribution of cuara, dos reales and peseta ('quarter', the US 25-cent coin) across New Mexico and southern Colorado

Figure 4.4 Distribution of salarata and soda de(l) martillo ('baking soda') across New Mexico and southern Colorado

Figure 5.1 Tokens of aspirated syllable- and word-final /s/ according to individual consultants' use of Spanish

Figure 5.2 Tokens of deletion of syllable- and word-final /s/ according to individual consultants' use of Spanish

Figure 6.1 Average proportion of sample accounted for by merged forms, by speaker group and vowel pairing (English)

Figure 6.2 Average proportion of sample accounted for by merged forms, by speaker group and vowel pairing (Spanish)

Figure 6.3 Average proportion of sample accounted for by production of $/ \mathrm{v} /$ as $[\mathrm{b}]$ in spoken Spanish, by speaker group

Figure 7.1 Map of the Minho River in Portugal and Spain (Norman Einstein, 25.8.2005. Permission is granted to copy, distribute and/or modify this document under the terms of the GNU Free Documentation License)

Figure 8.1 Map of research area

Figure 8.2 Perception of the placement and extent of the Geordie dialect area, by English respondents

Figure 8.3 Scottish (left) and English (right) respondents' perceptions of dialect variation in Scotland

Figure 8.4 Scottish (left) and English (right) respondents' perceptions of dialect variation in England

Figure 8.5 Commuting flows from Interaction Data Districts in southern Scotland (left) and northern England (right)

Figure 9.1 Two examples of 'parallel texting' in public signage in Wales

Figure 9.2 Cwtch Restaurant's St David's Day menu, 2012

Figure 10.1 Contrasting maps of the eastern Republic of Ireland/Northern Ireland border area

Figure 10.2 Crossing the border, Dublin-Belfast motorway (upper portion of image, long-distance view; lower portion, close-up of NI signage)

Figure 10.3 Main road signs, Monaghan (ROI, left) and Armagh (NI, right)

Figure 10.4 Street signs in Dundalk (ROI, upper portion of image) and Newry (NI, lower portion of image) 
Figure 10.5 Dog notices, Carrickmacross (ROI, left) and Warrenpoint (NI, right)

Figure 10.6 Irish language with cultural reference in Monaghan (ROI, left) and Armagh (NI, right)

Figure 10.7 Bilingual street signage, Warrenpoint (NI, upper portion of image) and Monaghan (ROI, lower portion)

Figure 10.8 Irish-language reference, commemoration and historical layering, Newry (NI)

Figure 10.9 Alcohol-free zone notices, Warrenpoint (NI, leftmost image) and Monaghan (ROI, centre and rightmost image)

Figure 10.10 Polish shop (Armagh, NI) and branch of Lituanica chain (Carrickmacross, ROI)

Figure 11.1 Visual Analogue Scale used in attitude questionnaire

Figure 11.2 Languages spoken at home by students originating from different ethnic backgrounds

Figure 11.3 Languages spoken with friends by students from different ethnic backgrounds

Figure 11.4 Relationship between students' ethnic background and choice of questionnaire language

Figure 11.5 Affective attitudes towards Luxembourgish among students from different ethnic groups

Figure 11.6 Affective attitudes towards Luxembourgish among students who chose different questionnaire languages

Figure 11.7 Attitudes towards the usefulness of Luxembourgish among students from different ethnic backgrounds

Figure 11.8 Attitudes towards the usefulness of Luxembourgish among students who chose different questionnaire languages

Figure 11.9 Attitudes towards Luxembourgish as a language of integration among students who chose different questionnaire languages (French, German or Luxembourgish)

Figure 11.10 Attitudes towards Luxembourgish as a language of integration among students from different ethnic backgrounds

Figure 11.11 Attitudes towards the usefulness of French among students from different ethnic backgrounds

Figure 12.1 The Rhône-Alpes region in France, and the main provinces that existed in south-eastern France before the Revolution

Figure 12.2 Départements of Rhône-Alpes

Figure 12.3 The traditional dialectological boundary between Francoprovençal and Occitan in Rhône-Alpes (map courtesy of the Rhône-Alpes region; this map is used by the regional government when promoting its languages)

Figure 12.4 Occitan dialects in France, Italy (eleven valleys in Piedmont) and Spain (the Val d'Aran in Catalonia)

Figure 12.5 The $c a / c h a$ heterogloss separating northern and southern Occitan dialects. $K=/ \mathrm{k} / ; \operatorname{tch}=/ \mathrm{t} \int / ; \operatorname{ch}=/ \int / ; s=[\theta]$ 
Figure 12.6 Roman roads from Lyon to Aoste and Geneva, and the Francoprovençal domain

Figure 12.7 Heteroglosses running from east to west in the Drôme département (based on Bouvier 1976)

Figure 12.8 The southern part of Rhône-Alpes, according to the Occitan movement

Figure 12.9 The same zone as that shown in Figure 12.8, according to promoters of Provençal as a distinct language

\section{Extracts}

Extract 8.1 Extract from interview with respondents from Hexham

Extract 8.2 Extract from interview with respondents from Brampton

Extract 9.1 The Welsh national anthem

Extract 9.2 Extracts from Iaith Pamb (paragraphs 2.12-2.17) 